\title{
Changes in the quality of life following surgery for hyperhidrosis
}

\author{
Davide Patrini ${ }^{1}$, Iulia Bujoreanu ${ }^{2}$, Savvas Lampridis ${ }^{1}$, José Ribas Milanez de Campos ${ }^{3}$, Benedetta Bedetti ${ }^{4}$, \\ Hugo Veiga Sampaio da Fonseca ${ }^{3}$, David Lawrence ${ }^{1}$, Paulo Kauffman ${ }^{5,6}$, Nelson Wolosker ${ }^{5,6}$ \\ ${ }^{1}$ Thoracic Surgery Division, University College London Hospitals (UCLH), London, UK; ${ }^{2}$ Department of Cancer and Surgery, Imperial College \\ London, London, UK; ${ }^{3}$ Thoracic Surgery Division, Heart Institute/Clinics Hospital from University of São Paulo Medical School, São Paulo, Brazil; \\ ${ }^{4}$ Thoracic Surgery Division, Malteser Hospital, Bonn, Germany; ${ }^{5}$ Vascular Surgery Division, Albert Einstein Israelite Hospital, São Paulo, Brazil; \\ ${ }^{6}$ Vascular and Endovascular Division, Clinics Hospital from University of São Paulo Medical School, São Paulo, Brazil \\ Contributions: (I) Conception and design: D Patrini, JRM de Campos; (II) Administrative support: D Lawrence; (III) Provision of study material \\ or patients: P Kauffman, N Wolosker; (IV) Collection and assembly of data: B Bedetti, HVS da Fonseca; (V) Data analysis and interpretation: I \\ Bujoreanu, S Lampridis; (VI) Manuscript writing: All authors; (VII) Final approval of manuscript: All authors. \\ Correspondence to: Mr. Davide Patrini, MD. UCLH in Westmoreland St. 16-18 Westmoreland St., W1G 8PH London, UK. \\ Email: davide.patrini@nhs.net.
}

\begin{abstract}
Hyperhidrosis is characterized by diaphoresis that is unrelated to the physiological thermoregulatory requirements of the body. Primary hyperhidrosis is caused by an idiopathic overactivity of the sympathetic nervous system and can affect the axillae, in more than half of the cases, palms, soles and face. As a result, patients may develop psychologic disorders, such as anxiety and depression, or experience impaired quality of life (QOL). Set of indicators were therefore introduced to describe the relationship between QOL post-surgery for hyperhidrosis and daily life. Recently a World Health Organization study group developed a questionnaire made of 100 question ranging from physical, psychological, environmental and spiritual aspects (WHOQOL0-100); this has been followed by a shorter one (WHOQOL BREF) easier to be completed maintaining the same standard of psychometric assessment. This is made of 26 questions covering the same aspects as the WHOQOL-100 representing however a generic tool to assess QOL. Nevertheless there are other QOL indicators that have to be considered when assessing the impact of primary hyperhidrosis $(\mathrm{PH})$ and postoperative status following surgery for $\mathrm{PH}$.
\end{abstract}

Keywords: Hyperhidrosis; sympathectomy; quality of life (QOL); surgery

Received: 29 September 2019; Accepted: 29 November 2019; Published: 10 April 2020.

doi: $10.21037 /$ shc. 2019.12 .03

View this article at: http://dx.doi.org/10.21037/shc.2019.12.03

\section{Introduction}

Hyperhidrosis is characterized by diaphoresis that is unrelated to the physiological thermo-regulatory requirements of the body. Primary hyperhidrosis is caused by an idiopathic overactivity of the sympathetic nervous system and can affect the axillae, in more than half of the cases, palms, soles and face (1). As a result, patients may develop psychologic disorders, such as anxiety and depression, or experience impaired quality of life (QOL).

It is estimated that approximately $1-1.6 \%$ of the population in the United Kingdom and the US seek medical advice for excessive sweating (2). Recently, a sample of the
US population was studied using a questionnaire, which aimed to establish the patient's self-perception in relation to their sweat. The authors found that the prevalence of selfreported hyperhidrosis was as high as $4.8 \%$ and only $51 \%$ of these patients had tried talking about this problem with a healthcare professional (1).

Disease can range in severity and QOL is a main indicator for physical, mental and emotional well-being. As excessive sweating is associated with discomfort and embarrassment, this interferes with the activities of daily living and affects work, leisure and social activities. The psychosocial aspect must not be left aside; patients with palmar primary hyperhidrosis, may struggle to manipulate 
papers and other similar materials. The perception for this condition is not suffered only by the patients but also to those around them triggering anxiety, suffering leading to isolation without considering the fact that this condition can be also be considered disabling or even dangerous in certain aspect of the professional sphere.

Axillary primary hyperhidrosis is the most common type and it also has a debilitating social impact. Bechara et al. assessed fifty-one patients with axillary primary hyperhidrosis. Following nine months of treatment, QOL questionnaires were used to evaluate the outcomes. The conclusion was that surgical therapy could reduce by almost $80 \%$ the disabilities caused by excessive axillary PH (3).

Craniofacial primary hyperhidrosis, with or without blushing, is considered embarrassing on a social and professional level. It can also be associated with social phobia and anxiety disorders, and it can aggravate psychiatric disorders. We can conclude that craniofacial $\mathrm{PH}$ has a deep impact in the psychic of the patient considering the steep decrease in QOL observed (4).

Whereas no evidence is given that primary hyperhidrosis is a psychiatric disorder, these individuals might be at an increased risk of developing certain psychological disorders such as anxiety (5). For this reason, QOL assessments are a valid indicator of psychosocial impact in primary hyperhidrosis.

Minimally invasive thoracic sympathectomy (VATS) is considered to be the safest and most effective treatment of $\mathrm{PH}$ both in adults and children. Although different studies suggest that the surgical management can be offered in the treatment of patients from the age of five, VATS is classically offered to in children over 7 in order to restore stable psychomotor development (6).

\section{Evaluation of the QOL in patients with hyperhidrosis}

Different studies applied adapted questionnaires to assess QOL following sympathectomy for primary hyperhidrosis (7-10). Questionnaires like the Medical Outcomes Study Short Form 36 (SF-36), the Spielberger State Trait Anxiety Inventory (STAI), the Zung Self-Rating Depression Scale (SDS), and the Dermatology Life Quality Index (DLQI): despite the easy applicability and relatively good validation through clinical studies, these adapted questionnaires are limited in primary hyperhidrosis due to its complexity and specificity. Despite their limitations, the benefits of VATS in improving QOL in primary hyperhidrosis patients are unquestionable, especially when evaluating the emotional and social aspects in the patient experience.

As a consequence to accurately assess QOL in patients with primary hyperhidrosis we strongly believe that a specific questionnaire is required. Amir et al. describes the early stages of preparing a specific health questionnaire to assess the impact of primary hyperhidrosis on the QOL of these patients (11). We therefore developed the first questionnaire specifically tailored to assess QOL in patients with primary hyperhidrosis following VATS.

The initial design by Amir et al. included two psychology students interviewing primary hyperhidrosis surgery candidates from fifteen to thirty-five years old from a wide range of social backgrounds. Patients were then invited to include all the situations they think are affected by the primary disorder ranging from work, personal, interpersonal and leisure. The interviewers assisted by a multidisciplinary team of psychologist, psychiatrist and surgeon reviewed all the interviews identifying four domains as the most important: social, functional, social and emotional. Emotion was divided into two areas: "selfemotional", the assessment of how primary hyperhidrosis emotionally impacts patients; and "other-emotional", to evaluate patients' feeling about what the outer environment think about their problem. These areas were further defined by taking into consideration the various situations in which primary hyperhidrosis decisively interfered in the QOL of patients. However, a major downside of the Amir et al. study, recognized by the authors, was selection bias, as it looked at patients with more severe disease.

\section{Methods}

\section{Specific QOL questionnaire for hyperbidrosis: our experience}

Considering our previous studies, we decided to split our questionnaire into four domains: functional social, personal, self-emotional and we also included special conditions that may have an impact on QOL. The first QOL questionnaire assessment was performed prior to the patient's initial consultation. Each patient received a handbook with information about primary hyperhidrosis and the different options of clinical and surgical treatment. Additional information included: expected results, complications, and post-operative complications. Following consultation and physical examination, surgical indication was confirmed and patient electively was booked for surgery. In the first 30 postoperative days, patients answered the second part 
of the questionnaire. The last postoperative questionnaire was delivered telephonically by a nurse-an independent observer without access to patient's records, after a minimum period of five years.

In order to evaluate the efficacy of treatment for primary hyperhidrosis is important to compare variations of QOL and its various aspects at different follow up periods. The protocol described below was based on analysis of QOL questionnaires proposed by the expert consensus of the Society of Thoracic Surgeons published in the Annals of Surgery in 2011 for surgical treatment of primary hyperhidrosis (12).

A proposed QOL questionnaire is shown in full in Figure 1 and is based on an article which received 107 citations in Web of Science ${ }^{\circledR}$ and 134 citations in $\operatorname{Scopus}^{\circledR}$ (13).

\section{Results}

\section{0 days follow-up}

In a period between 1995 and 2002, 403 patients (62\% female and $38 \%$ male) underwent VTS at Hospital das Clínicas from Universidade de São Paulo and were followed up with assessments of QOL, using the proposed questionnaire. The level of surgical resection of the sympathetic chain was decided according the localization of symptoms.

Furthermore, 217 (57\%) patients complained of plantar and palmar hyperhidrosis; 95 patients (25\%) of palmar, axillary, and plantar hyperhidrosis; 60 patients $(15.7 \%)$ of only axillary symptoms; and 25 patients $(6.5 \%)$ of facial symptoms.

Responses were divided as follows: "Better" in "Much better" and "Slightly better"; "Worse" in "Slightly worse" and "Much worse".

Results showed that 292 (72.4\%) "Much better"; 95 (23.6\%) "Slightly better"; 12 (3.0\%) "Same"; four (1.0\%) "Slightly worse"; and zero (0\%) "Much worse". From these responses, 387 (96.1\%) patients reported improvement in QL in the immediate postoperative period.

Thorough analysis of questionnaire demonstrated that in the preoperative period, $87.6 \%$ of patients rated QOL as "Bad" or "Very bad". Thirty days later, 96\% classified QOL as "Better" or "Slightly better", despite in a very short follow up time.

Among the proposed fields, we found that the most affected was the "functional-social", i.e., the one that relates to practical matters of everyday life. This observation was made in both early and late follow-up (13). Moreover, this domain was one of the most chosen as first and second options. Thus, this questionnaire shows how primary hyperhidrosis negatively affects almost all daily activities. The 'personal' domain was also significantly improved, as patients gained much more confidence in their personal relationships soon after surgery. Another important finding to highlight is that the second most chosen domain was the "emotional" one, indicating that the patients were extremely pleased to no longer justify their symptoms or face rejection from others.

\section{Discussion}

Of note, Amir et al. reported on three parameters, which have also been investigated in our study population, with rather interesting results. The first is associated with gender. In their study, women exhibited an initial decline in the score for most domains of QOL compared to men, apart from the emotional component. A possible explanation for this difference is the increased likelihood for women to seek early medical advice to limit the impact on their emotional sphere. Contrariwise, it could be assumed that men tend to be more tolerant of aesthetically unpleasant conditions. Nevertheless, in our study there was no significant association between QOL scores and gender, with similar variation in the total distribution in both men and women.

The timing of symptoms also plays a big role: we noticed that in patients suffering from primary hyperhidrosis since childhood the QOL scores were significantly lower comparing to patients whose autonomic dysfunction started after puberty, adolescence or childhood: the earliest is the exposure to stressful social situations related to primary hyperhidrosis, the lightest is the perception to frustrating and embarrassing situations related to the excessive sweating. Corroborating this view, primary hyperhidrosis patients find it increasingly difficult to live or to get used to "embarrassing situations". Thus, the level of QOL decreases as patients live with the condition longer. In our sample, we identified a similar trend as the responses to QOL questionnaires correlated to patient age. QOL improvement tends to be more notable in patients under 18 years of age.

The third relevant observation is that in the functional social domain, the distress perceived is relative to the damage suffered. Anxiety plays also a role pushing patients to look for a more aggressive and definitive treatment. Amir ad co-authors highlighted that surgeons should consider 


\section{HEALTH RELATED QUESTIONNAIRE - HYPERHIDROSIS}

NAME: ...............................................................................

This study is RESTRICTED TO QUESTIONS CONCERNING YOUR WELL-BEING AND LIFE QUALITY, BEFORE AND AFTER SURGERY FOR CORRECTION OF HYPERHIDROSIS AND OR FACIAL BLUSHING/SWETTING. This information is important because we want to know how you feel and how well you are able to conduct your daily activities. Please answer each question marking only the answer as indicated. If you are in doubt about the answer, reread the question and try to answer to the best of your ability.

TABLE 01 Generally speaking, how would you rate your life quality BEFORE SURGERY?

\begin{tabular}{|l|l|}
\hline Excellent & 1 \\
\hline Very good & 2 \\
\hline Good & 3 \\
\hline Poor/Inferior & 4 \\
\hline Very poor/Inferior & 5 \\
\hline
\end{tabular}

TABLE 02. Compared to the period before surgery how would you rate your life quality AT LEAST 30 DAYS AFTER SURGERY?

\begin{tabular}{|l|l|}
\hline Much better & 1 \\
\hline Slightly better & 2 \\
\hline The same & 3 \\
\hline Slightly worse & 4 \\
\hline Much worse & 5 \\
\hline
\end{tabular}

ATTENTION: STARTING FROM THE NEXT QUESTION, PLEASE ALWAYS USE THE SCALE OF VALUES USED IN THE TWO TABLES ABOVE, SELECTING ONLY ONE CHOICE FOR EACH ANSWER. THIS QUESTIONNAIRE IS CONFIDENTIAL AND WILL BE UTILIZED ONLY FOR STUDY PURPOSES.

1) FUNCTIONAL / SOCIAL DOMAIN, with relation to the following items, how would you rate your quality of life:

\begin{tabular}{|c|c|c|c|c|c|c|c|c|}
\hline \multirow[b]{2}{*}{ Writing: } & \multicolumn{4}{|c|}{ Before surgery: } & \multicolumn{4}{|c|}{ After surgery } \\
\hline & 12 & 3 & 4 & 5 & 1 & 2 & 3 & 4 \\
\hline Doing manual work: & 12 & 3 & 4 & 5 & 1 & 2 & 3 & 4 \\
\hline Doing recreation: & 12 & 3 & 4 & 5 & 1 & 2 & 3 & 4 \\
\hline Doing sports: & 12 & 3 & 4 & 5 & 1 & 2 & 3 & 4 \\
\hline Shaking hands: & 12 & 3 & 4 & 5 & 1 & 2 & 3 & 4 \\
\hline Being with friends (public places): & 12 & 3 & 4 & 5 & 1 & 2 & 3 & 4 \\
\hline Grasping objects: & 12 & 3 & 4 & 5 & 1 & 2 & 3 & 4 \\
\hline Social dancing: & 12 & 3 & 4 & 5 & 1 & 2 & 3 & 1 \\
\hline
\end{tabular}

2) PERSONAL DOMAIN, with your partner / spouse. How would you rate your quality of life:

Holding hands:

Intimate touching:

Intimate affairs:

\begin{tabular}{ccccccccccc}
\multicolumn{3}{c}{ Before surgery: } & \multicolumn{4}{c}{ After surgery: } \\
1 & 2 & 3 & 4 & 5 & 1 & 2 & 3 & 4 & 5 \\
1 & 2 & 3 & 4 & 5 & & 1 & 2 & 3 & 4 & 5 \\
1 & 2 & 3 & 4 & 5 & & 1 & 2 & 3 & 4 & 5
\end{tabular}

3) EMOTIONAL-SELF or OTHERS; how would you rate the fact that after sweating/blushing excessively:

I always justified myself:

People rejected you slightly:

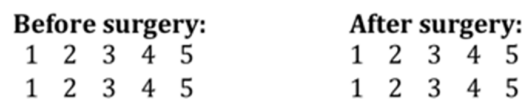

4) UNDER SPECIAL CIRCUMSTANCES - How would you rate your quality of life:

In a closed or hot environment:

When tense or worried:

Thinking about the problem:

Before an examination/meeting/speaking in public:

Wearing sandals /walking barefoot:

Wearing colored clothing:

Having problems at school / work:

\begin{tabular}{|c|c|c|c|c|c|c|c|c|}
\hline \multicolumn{5}{|c|}{ Before surgery: } & \multicolumn{4}{|c|}{ After surgery: } \\
\hline 1 & 2 & 3 & 4 & 5 & 12 & 3 & 4 & 5 \\
\hline 1 & 2 & 3 & 4 & 5 & 12 & 3 & 4 & 5 \\
\hline 1 & 2 & 3 & 4 & 5 & 12 & 3 & 4 & 5 \\
\hline 1 & 2 & 3 & 4 & 5 & 12 & 3 & 4 & 5 \\
\hline 1 & 2 & 3 & 4 & 5 & 12 & 3 & 4 & 5 \\
\hline 1 & 2 & 3 & 4 & 5 & 12 & 3 & 4 & 5 \\
\hline 1 & 2 & 3 & 4 & 5 & 12 & 3 & 4 & 5 \\
\hline
\end{tabular}

Figure 1 Proposed quality of life questionnaire. 
these facts when assessing a patient for surgery in order also to foresee the impact of surgery. To analyze the outcome, the simplest way is to have patients choosing among the three domains according to their preference. In each case, an idea of which domain had the biggest improvement on QOL would be elucidated.

\section{Conclusions}

Specific questionnaires are to be considered the best way to evaluate the impact of Primary Hyperhidrosis on the QOL, avoiding generic models that are not taking into consideration the variability among individuals. These tailored questionnaires should include four domains: functional, social interpersonal and emotional.

Our data confirmed that the QOL improves significantly in the short term following surgical sympathectomy. In the longer term a sustained improvement is seen but further data are required to better assess the QOL after 5 and 10 years.

\section{Acknowledgments}

Funding: None.

\section{Footnote}

Provenance and Peer Review: This article was commissioned by the Guest Editors (Federico Raveglia and Marco Scarci) for the series "Hyperhidrosis Management: from Diagnosis to Therapy" published in Shangbai Chest. The article has undergone external peer review.

Conflicts of Interest: All authors have completed the ICMJE uniform disclosure form (available at http://dx.doi. org/10.21037/shc.2019.12.03). The series "Hyperhidrosis Management: from Diagnosis to Therapy" was commissioned by the editorial office without any funding or sponsorship. The author has no other conflicts of interest to declare.

Ethical Statement: The authors are accountable for all aspects of the work in ensuring that questions related to the accuracy or integrity of any part of the work are appropriately investigated and resolved.

Open Access Statement: This is an Open Access article distributed in accordance with the Creative Commons
Attribution-NonCommercial-NoDerivs 4.0 International License (CC BY-NC-ND 4.0), which permits the noncommercial replication and distribution of the article with the strict proviso that no changes or edits are made and the original work is properly cited (including links to both the formal publication through the relevant DOI and the license). See: https://creativecommons.org/licenses/by-nc-nd/4.0/.

\section{References}

1. Doolittle J, Walker P, Mills T, et al. Hyperhidrosis: an update on prevalence and severity in the United States. Arch Dermatol Res 2016;308:743-9.

2. Ricchetti-Masterson K, Symons JM, Aldridge M, et al. Epidemiology of hyperhidrosis in 2 populationbased health care databases. J Am Acad Dermatol 2018;78:358-62.

3. Bechara FG, Gambichler T, Bader A, et al. Assessment of quality of life in patients with primary axillary hyperhidrosis before and after suction-curettage. J Am Acad Dermatol 2007;57:207-12.

4. Sciuchetti JF, Ballabio D, Corti F, et al. Endoscopic thoracic sympathectomy by clamping in the treatment of social phobia: the Monza experience. Minerva Chir 2006;61:417-20.

5. Davidson JR, Foa EB, Connor KM, et al. Hyperhidrosis in social anxiety disorder. Prog Neuropsychopharmacol Biol Psychiatry 2002;26:1327-31.

6. Lin TS. Transthoracic endoscopic sympathectomy for palmar hyperhidrosis in children and adolescents: analysis of 350 cases. J Laparoendosc Adv Surg Tech A 1999;9:331-4.

7. Kumagai K, Kawase H, Kawanishi M. Health-related quality of life after thoracoscopic sympathectomy for palmar hyperhidrosis. Ann Thorac Surg 2005;80:461-6.

8. Swan MC, Paes T. Quality of life evaluation following endoscopic transthoracic sympathectomy for upper limb and facial hyperhydrosis. Ann Chir Gynaecol 2001;90:157-9.

9. Lau WT, Lee JD, Dang CR, Lee L. Improvement in quality of life after bilateral transthoracic endoscopic sympathectomy for palmar hyperhydrosis. Hawaii Med J 2001;60:126, 137.

10. Fredman B, Zohar E, Shachor D, et al. Video-assisted transthoracic sympathectomy in the treatment of primary hyperhidrosis: friend or foe?. Surg Laparosc Endosc Percutan Tech 2000;10:226-9.

11. Amir M, Arish A, Weinstein $Y$, et al. Impairment in quality 
of life among patients seeking surgery for hyperhidrosis (excessive sweating): preliminary results. Isr J Psychiatry Relat Sci 2000;37:25-31.

12. Cerfolio RJ, De Campos JR, Bryant AS, et al. The Society of Thoracic Surgeons expert consensus for the

doi: $10.21037 /$ shc.2019.12.03

Cite this article as: Patrini D, Bujoreanu I, Lampridis S, de Campos JRM, Bedetti B, da Fonseca HVS, Lawrence D, Kauffman P, Wolosker N. Changes in the quality of life following surgery for hyperhidrosis. Shanghai Chest 2020;4:20. surgical treatment of hyperhidrosis. Ann Thorac Surg 2011;91:1642-8.

13. de Campos JR, Kauffman P, Werebe Ede C, et al. Quality of life, before and after thoracic sympathectomy: report on 378 operated patients. Ann Thorac Surg 2003;76:886-91. 